\title{
THE CASCADE EFFECT OF COLLABORATIVE INNOVATION IN INFRASTRUCTURE PROJECT NETWORKS
}

\author{
Ruixue ZHANG ${ }^{1}$, Xiaolong XUE², Yuanxin $\mathrm{ZHANG}^{2 *}$ \\ ${ }^{1}$ School of Business Administration, Liaoning Technical University, Liaoning, China \\ ${ }^{2}$ School of Management, Guangzhou University, Guangzhou, China
}

Received 28 December 2019; accepted 8 February 2021

\begin{abstract}
As infrastructure projects get larger and more complex, innovation, which is highly dependent on collaboration and interactions among stakeholders, is critical to meet the challenges. Nevertheless, the existing literature is lacking in terms of studies into the spread of cooperative behaviors in infrastructure project innovations, on which project success is highly contingent. Hence, based on network science theories, this study aims to shed light on the cascade processes of cooperative behaviors in the evolution of collaborative innovations within infrastructure project networks and the impact of various network structures on the cascade effect. The results indicate that the number of initial innovation adopters is positively correlated with the role that the initial adopters play and the cascade effect of collaborative innovation on infrastructure projects. It is also shown that the cascade effect of collaborative innovations is contingent on project network structures. Furthermore, the results also suggest that network connection is positively correlated with cascade speed, scale, and time to reach a stable state. This study is the first to explore the cascade effect of stakeholders' interactions vis-a-vis collaborative innovation in infrastructure projects. The findings could assist policy-makers and project managers in taking appropriate measures to encourage innovation in infrastructure projects.
\end{abstract}

Keywords: infrastructure projects, collaborative innovation, cascade effect, cooperative behavior cascade, social network analysis, construction industry.

\section{Introduction}

Infrastructure provides services that meet most basic needs of human communities in economic development and social well-being (Hallegatte et al., 2019). Its development has been a high priority for global government agencies over many decades. Nonetheless, rapid urban population growth around the world in recent decades has led to a dramatic increase in larger and more complex infrastructure systems. Additionally, the construction industry is facing stricter environmental regulations as well as fierce competition. These internal and external challenges combined have become the main drivers of innovation (Bossink, 2004), although it should be noted that the construction industry is notorious for its lack of innovation (Holmen et al., 2005; Lu et al., 2015).

With the continuous increase in scale and complexity, an individual contractor is limited by the resources and information they possess (Son \& Rojas, 2011); hence, the success of infrastructure projects requires innovation and collaboration among different stakeholders through- out the project lifecycle (Han et al., 2018). Inter-organizational collaboration is a "must" for innovation (Bossink, 2007; Calamel et al., 2012) and requires highly integrated technologies and the expertise of multiple stakeholders (Loosemore, 2015) to fulfill project requirements. Collaborative innovation in infrastructure projects is also characterized by the resource amalgamation of cross-organization stakeholders (Rutten et al., 2009), which entails a systematic optimization process, rather than a simple accumulation of innovation resources among stakeholders at various levels.

The requirement for integration of the technologies, expertise, and resources of project stakeholders indicates that collaborative innovation involves intensive interactions (Han et al., 2018), which can have critical impacts on the outcomes of innovation (Baiden et al., 2006). What differentiates the interactions in construction innovation is that the industry is characterized by substantive fragmentation, which complicates the process and, in turn,

${ }^{*}$ Corresponding author. E-mail: yuanxin@gzhu.edu.cn 
calls for more interaction (Herrera et al., 2020). Hence, it is imperative to study the underlying mechanism of interactions among stakeholders in the course of infrastructure project innovation (Vespignani, 2009). Unlike the existing literature, which mainly focuses on coordination between entities (Kearns et al., 2006, 2009; Hong et al., 2017), this research studies the spread of cooperative behaviors through the interaction processes in innovation during infrastructure project execution because cooperative behaviors are decisive to innovation outcomes and quality (Han et al., 2018).

The spread of behaviors (e.g., weight loss, charitable giving, and positive attitudes) arises through the diffusion and uptake of social norms or other psychosocial mechanisms, like various types of innate mimicry (Collins, 2004). Fowler and Christakis (2010) showed that after observation of cooperative behavior, various mechanisms, including innate mimicry, trigger the transmission of those behaviors across social network connections in sequence to others not involved in the original interaction. This cooperative behavior cascade is thus subject to social contagion influences (Fowler \& Christakis, 2010; Hong et al., 2016) because individuals are greatly influenced by those they interact with (Fehr \& Fischbacher, 2004; Weber \& Murnighan, 2008). Most previous research has only studied or assumed a two-degree (from person to person) form of behavior spreading in collaborative innovation, which is incongruous with practical realities and, as such, poses limitations. This research expands the previous efforts to three degrees (from person to person to person) of cooperative behavior spread in collaborative innovation during infrastructure project implementation.

Heterogeneities across different organizations involved in infrastructure projects are a challenge to collaborative innovation due to the temporary nature of such endeavors. A temporary team, a common arrangement in project management (Cornick \& Mather, 1999; Herrera et al., 2020), can be seen as a complex system comprised of heterogeneous individuals that are autonomous, short-term goal-oriented, and situated in an environment in which their aggregated behaviors emerge from local interactions (Bertelsen, 2003; Son \& Rojas, 2009). Under such a temporary arrangement, contradictory findings can become manifest: one study claims that unstructured interaction with others in large populations significantly reduces the likelihood of cooperation (Enquist \& Leimar, 1993); while other research shows that heterogeneity in the interaction topology can improve the prospects for cooperation (Santos et al., 2008).

Most cooperative behavior research is based on game theory, assuming an adversarial relationship among stakeholders (Ohtsuki et al., 2006; Son \& Rojas, 2011). Cooperative contracting methods (e.g., Design-Build, Construction Management/Project Manager, and Integrated Project Delivery) are gaining increasingly more popularity in infrastructure projects to encourage innovation (Zhang et al., 2018). Further, tasks are highly interdependent between various specialized firms involved in an infrastructure project, and interactions typically occur between individuals. Cooperation in a project team entails reasoning strategically with bounded rationality and interacting with other individuals in a dynamic environment. As individuals' interaction behaviors can be altered by pressures from social norms or innate mimicry, the influence of neighboring individuals should be explored to accommodate collaborative processes in a temporary project team. Quite distinct from prior work, this study focuses on whether stakeholder interactions can create cascades of cooperative behaviors, spreading from person to person to person.

Network analysis can visualize interactions and communication patterns among project stakeholders (Mead, 2001) and has been applied to understand collaboration between firms in infrastructure projects (Pryke, 2004; Sandhu \& Helo, 2006). Skyrms and Pemantle (2000) and Jackson and Watts (2002) studied the interactions among players in games and showed payoffs by players' reinforced interactions in dynamic social networks. Focusing more on social network properties, Hanaki et al. (2007) probed the evolution of cooperative behaviors in networks, in which players' behaviors and interaction structures coevolve. The potential of network analysis in exploring relationships, behaviors, and operating patterns within project organizations has been substantiated by research conducted over the past two decades (Han et al., 2018; Herrera et al., 2020; Lin, 2015; Lee et al., 2018; Zhu \& Mostafavi, 2017). Unlike many other related studies that are interested in how network structures affect communication and information exchange, the focus herein is on how network structures alter collaborative behaviors in innovation and how heterogeneous partners are coordinated in a project network.

To reveal the evolution of collaborative innovation and behavior cascades in infrastructure projects, this paper explores how different network structures improve or stifle collaborative innovation in project teams. Specifically, this study maps a project network based on relations among project stakeholders under each contracting method to explain the evolution of collaborative innovation via simulating the cascade effect caused by different network structures.

The remainder of the paper is organized as follows. The next section provides definitions of the critical concepts involved in this study. The social network model for the behavior cascade in collaborative innovation is then introduced in terms of configuration and parameterization. The cascading process of collaborative innovation is then analyzed based on different network attributes through sensitivity analysis. The penultimate section focuses on validation finally, conclusions are offered including limitations and suggestions for future research in this domain. 


\section{Critical concepts}

\subsection{Collaborative innovation}

Collaborative innovation is a reciprocal process whereby two or more individuals or organizations work together to share resources and knowledge in order to reap the maximum benefits for all. Collaborative innovation includes two dimensions: integration and interaction (Serrano \& Fischer, 2007). Integration involves reorganization of knowledge, resources, actions, and performance; and interaction refers to mutual knowledge sharing, optimal allocation of resources, optimal coordination of actions, and systems congruence.

Open innovation is defined as "... the use of purposive inflows and outflows of knowledge to accelerate internal innovation, and expand the markets for external use of innovation, respectively" (Chesbrough et al., 2006). According to the concept of open innovation, the boundary of organizational innovation activities is vague, and it emphasizes the integration of internal and external resources. Similar to open innovation, collaborative innovation has become another important innovation mode, which leads to a nonlinear utility of system superposition (Baldwin \& Von Hippel, 2011). However, collaborative innovation is more complex and involves multi-agent collaborative interactions, which result in systematic, superimposed, and nonlinear effects through in-depth cooperation and resource integration among innovation entities.

The essence of collaborative innovation lies in the process of systematic optimization of each innovation element. Through guidance and administrative measures, industries may form a large integrated innovation organization mode, which is a new paradigm to improve innovation capabilities and outcomes (Bhaskarabhatla \& Hegde, 2014; Girmscheid \& Rinas, 2012; Kapsali, 2011; Powell et al., 1996). By virtue of strong integration and numerous participants, multi-agent cooperation can augment technological innovation in contexts such as mega infrastructure projects (Yepes et al., 2016). These features can also serve to transform and upgrade projects in terms of efficiency and environmental protection, which is crucial to achieving high performance and sustainability in the construction industry. Hence, collaborative innovation networks feature multi-agent collaborative interactions, and emphasize deep cooperation and resource integration for knowledge creation and technological innovation (Powell et al., 1996).

\subsection{Cascade effect}

The cascade effect, also known as information cascade, refers to the clustering process in decision-making (Bikhchandani et al., 1992; Welch, 1992; Hong et al., 2016, 2017). Specifically, when making a sequence of decisions, the behaviors of early decision makers are witnessed by their later counterparts. In this process, the early decision makers (predecessors) pass the information they have obtained to their successors, who in turn may abandon their prior information in favor of imitating the decisions of their predecessors (Bikhchandani et al., 1992). However, in the cascading process, individuals do not blindly imitate others' behaviors. Instead, this only occurs when predecessors' decisions conveyed meaningful information, or when the succeeding decision makers feel pressure from social compliance, which is essentially rooted in the idea of information cascading (Collins, 2004). There are some prerequisites to evoking the cascade effect. For instance, each actor (node) can only make one decision at a time within a certain timeframe. The succeeding decision makers can observe the behaviors of the predecessors in a sequence of decision-making and use the information to assist decision-making.

The cascade effect of collaborative innovation in infrastructure projects refers to the cascade effect of information transmission, communication, and mutual learning through interaction and acceptance of information regarding the innovation decision-making behaviors of other organizations. The essence of the cascade effect in collaborative innovation in an infrastructure project team is that cooperative behaviors spread from person to person to person in a temporary coalition. According to social learning theory, people learn the behaviors of others through direct experience. The theory posits that when one observes the behaviors of others and notices the positive side, one is likely to imitate those behaviors.

There are two primary benefits of imitating others' positive behaviors in collaborative innovation. On the one hand, the preceding decision makers provide useful information for successors' behavior change in decision-making. On the other, the successors are rewarded by copying others' behaviors. This research focuses on the spread of individual decision-making in innovation. Several studies promoting communication technology have corroborated the direct benefits: a few good examples would be the spread of telephone, fax, and e-mail technologies, suggesting that the driving force depends on whether communicatees have adopted the corresponding technologies (Fischer, 1992; Markus, 1987).

\subsection{Social network analysis}

A social network is comprised of nodes (actors) connected based on one or more specific types of relationship (i.e., ties), such as friendships, firm alliances, and international trade partners (Liu et al., 2015; Son \& Rojas, 2011). It is mapped as a graph with nodes representing the individual actors in the network and with links representing the relationships or ties between the actors (Zhu \& Mostafavi, 2017). Social network analysis (SNA) studies interactions between actors and the evolution of their relationships based on graph theory, using metrics (e.g., density, degree centrality, and betweenness centrality) to evaluate not only the overall network structure but also the location of the connected nodes (actors) (Lee et al., 2018; Moreno, 1960). SNA analyzes relationships of the nodes in a network through description, visualization, and statistical models (Van Duijn \& Vermunt, 2006). This research focuses on actors' relationships, rather than specific actors. 
Research focused on disease transmission (Klovdahl, 1985) and innovation diffusion (Abrahamson \& Rosenkopf, 1997) has pioneered use of SNA. Studies show that innovation diffuses faster in small-world networks than in both regular and random networks. Abrahamson and Rosenkopf (1997) discovered that individuals' perceptions of innovation depend on their position in the social network and the structure of the social network, which affects the order of receiving information and adopting innovation.

Over the past three decades, SNA has also been increasingly proposed to address organization and management issues, particularly network characteristics and effects posed by business organizations (Tichy et al., 1979). SNA provides a new perspective to gain insight into isolated individual actors within the organizational context, focusing on the relations or structured patterns of individual actors (Brass et al., 2004; Kilduff \& Tsai, 2003). As early as the 1950s, the construction industry was regarded as an organizational network (e.g., quasi-firms) (Stinchcombe, 1959), particularly in terms of its project-based teams (Taylor \& Levitt, 2007). The early SNA research in construction focused on communication problems among key individuals involved in a project network (e.g., clients, owner's representatives, architects, and construction managers) at the intra-organizational level rather than at the inter-organizational level (Loosemore, 1997, 1998).

SNA has also gained great popularity in construction management research over the past two decades. Construction project teams are regarded as social networks consisting of connected nodes of the construction participants, and their relationships must be analyzed in networks (Pryke, 2004). Law (2010) noted that SNA provides a tool for modeling and visualizing the relationships between projects, organizations, and tasks. Chinowsky et al. (2011) evaluated the importance of a task according to the degree of nodes using SNA and graph theory. SNA can provide a more relational, contextual, and holistic picture of project organizations in construction research (Borgatti \& Foster, 2003). It is used to study collaboration patterns. For example, Hossain (2009) explored the relationship between actors' (stakeholders') locations and their coordinative ability in a project organization network. He also conducted an empirical study to verify the positive correlation between the centrality of an individual actor and their coordination ability in a project network (Hossain, 2009). Several other studies have aimed to understand the characteristics of construction project networks due to the emerging view that project teams are temporary network-based organizations (Taylor \& Levitt, 2007; Turner \& Müller, 2003).

\subsection{Infrastructure project network and behavior cascade}

Infrastructure project success requires the collaboration of multiple organizations (Han et al., 2018; Liu et al., 2015; Lee et al., 2018) and highly interdependent individuals, involving intense interactions during the course of the project lifecycle (Herrera et al., 2020; Liu et al., 2015). The relationships between these entities involved in a project can be represented in a network and analyzed based on some mathematical metrics, like degree, betweenness, density, closeness, average degree of clustering, average path length, diameter, and modularity (Pryke, 2004). Project stakeholders are the nodes (actors) in a network, which can be evaluated by quantity and paired connections; and their relations contribute to the links (edges) connecting the nodes, which can be measured in terms of direction, strength of the relation, distance, and so on (Herrera et al., 2020; Zhu \& Mostafavi, 2017).

Individuals' decisions are influenced by others because cooperative behaviors transmit through imitation in social networks (Bond, 2019). According to characteristics of the network connections representing the participants in various organizations, the cascade effect of collaborative innovation in a construction project can be classified into three categories: the cascade effect of organization-organization, the cascade effect of organization-innovation activities, and the cascade effect of organization-innovation activities-organization.

Figure 1 represents a network consisting of leadermember relations of the participants in construction projects and illustrates the organization-organization cascade. It shows that the top nodes (organizations) directly influence the management decisions of the nodes below. For example, organization A directly affects organization $\mathrm{B}, \mathrm{C}$, and $\mathrm{D}$; then, organization $\mathrm{C}$ affects organization $\mathrm{E}$ and $\mathrm{F}$. The arrowed links (edges) connecting the nodes (organizations) indicate the direction of information flows among organizations. For instance, if organization A attempts to pass information to organization $\mathrm{E}$ and $\mathrm{F}$, it must go through $\mathrm{C}$. The information processing ability of organization C (e.g., transmission efficiency and distortion rate) directly affects interaction outcomes between organization A, E, and F; furthermore, it influences the trust and management efficiency between organizations (nodes).

Figure 2 represents an organization-to-innovation activities network, in which organization A is part of innovation activities a and $\mathrm{c}$ in a construction project. The decision-making behaviors of organization A directly affect the efficiency of innovation activities a and c. When other nodes participate in innovation activities a and c, the completion status of innovation activities a and $c$ of organization A affects the decision-making, degree of cooperation, and implementation of activity $c$ of organizations $B$ and C. This is defined as the cascade effect of organizationinnovation activities-organization. The upper-case letters (e.g., A, B, C, and D) stand for four different organizations in the project network, lower case letters (e.g., a, b, and c) denote three related activities in an innovation task. The red lines represent the execution relationship between the organization and the task, in which process organizations $\mathrm{A}, \mathrm{B}, \mathrm{C}$, and $\mathrm{D}$ have information exchange and communication (as shown by the black line) because they jointly participate in the three related tasks a, b, c of an innovation task. 


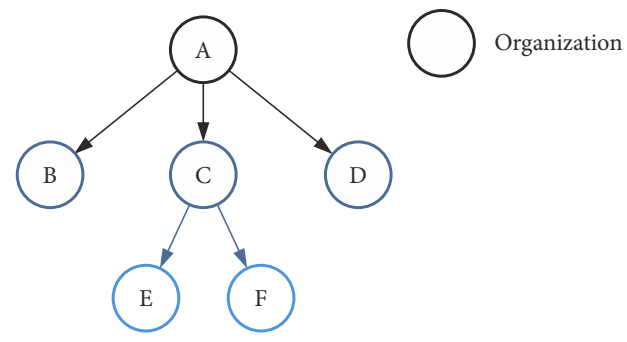

Figure 1. Cascade effect of project organization behaviors

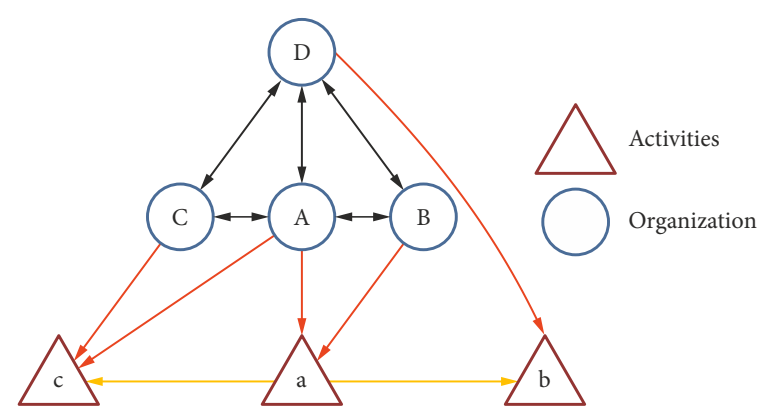

Figure 2. Cascade effect of organization-innovation activities in infrastructure projects

The susceptible-infected-recovered (SIR) model was introduced by Kermark and McKendrick (1927) to model disease spread in networks, and it is also suitable for cascading process simulation. In a project network, individuals (nodes) are connected and interact based on task interdependence. Individuals are infected by early adopters and then become part of the collaborative innovation due to the information passed from the early innovation adopters. Hence, these individuals become new adopters of the innovation. As the scope of information diffusion gradually increases, more and more participants acquire relevant information about the innovation, and more stakehold- ers understand the value of innovation. The continuous increase in innovation adopters creates social pressure to compel the decision makers to form a herd mentality, occasionally resulting in irrational behaviors in individuals' adoption decisions (Nowak, 2012). When potential adopters become real adopters, they spread innovation information through repeatedly contacting and interacting with others. Eventually, everyone in the network adopts innovation in ideal situations, forming a complete cascade of collaborative innovation in project networks. The cascade processes of collaborative innovation are illustrated in Figure 3, in which blue circles represent the innovation adopters, purple circles symbolize the potential adopters, and void circles denote non-adopters. In the cascading process, $t$ represents the stage of the process.

\section{Cascade effect of collaborative innovation}

\subsection{Network model specification}

Cascade processes were modeled as a sequential coevolution of behavioral dynamics at the micro level and network dynamics at the macro level. The simulation model seeks to reveal the dynamics of the cascade effect within a project network, in which each run denotes a step $t$ and the state of each node is expressed as a function of a binary variable related to time: $v_{i}(t) \in\{0,1\} \cdot v_{i}(t)=1$ denotes that node $i$ joined the cascade, turning into an innovation adopter; $v_{i}(t)=0$ represents node $i$ in a normal state of independence and has not yet adopted any innovations.

According to Watts and Strogatz's (1998) model, $P(k) k$ stands for an individual's decision, depending primarily on the state of the nearest adjacent nodes in the network. Under group pressure, individuals discard their original ideas in order to comply with the behaviors of the majority, and show a tendency to be consistent with the team in thinking and behavior. If the ratio of an innovation
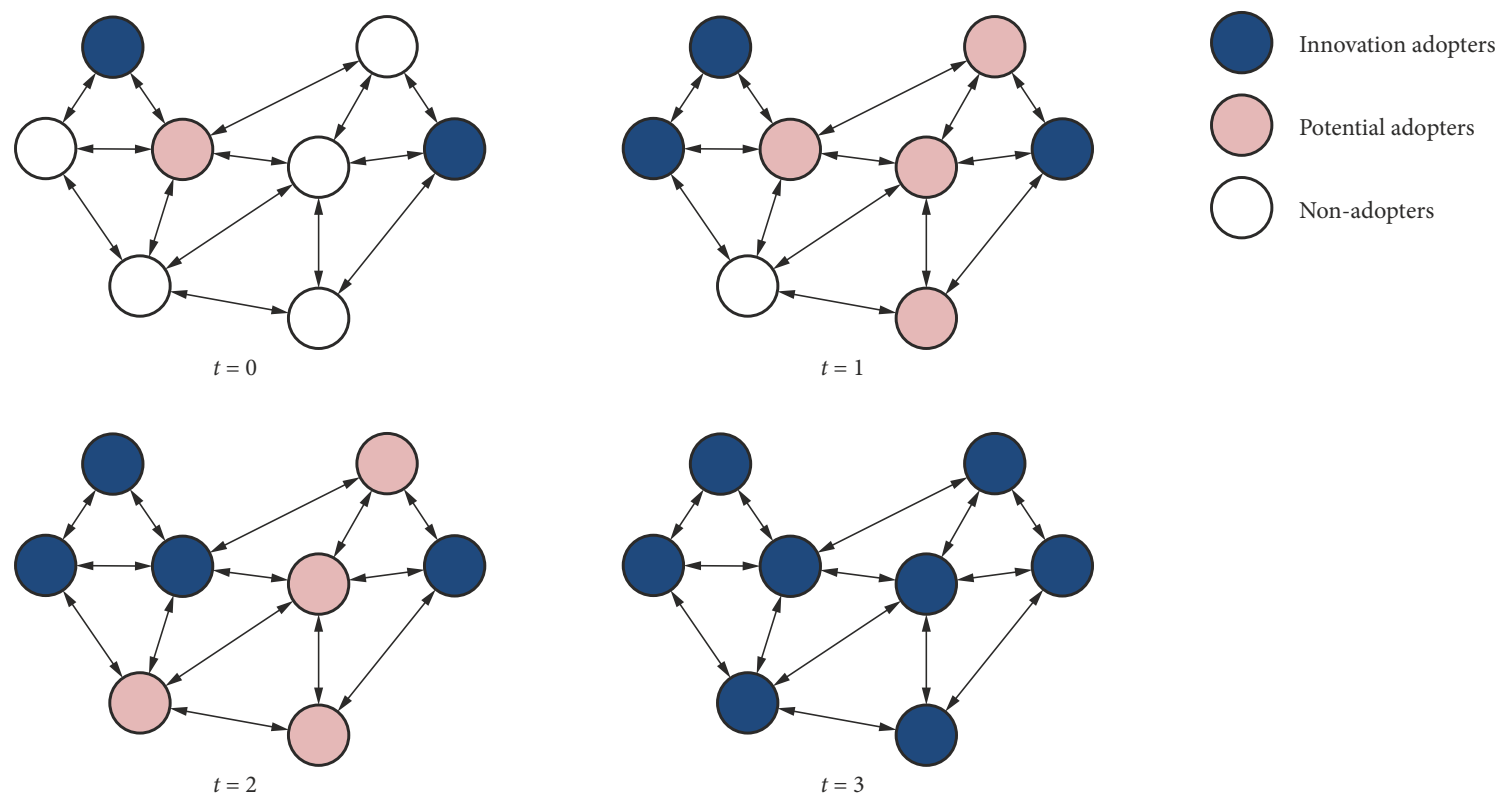

Figure 3. Cascade processes of collaborative innovation 
adopter's neighborhood is equal to or greater than the given threshold $d_{i}$, then the neighboring node becomes an innovation adopter. Therefore, assigning a threshold value $d_{i}$ to each node follows the probability distribution $f(d)$, which is regarded as the individual's preference in innovation. If the ratio of an innovation adopter's neighbor $i$ is less than the threshold value $d_{i}$, then node $i$ is seen in a normal state, meaning $v_{i}(t)=0$. If the ratio exceeds $d_{i}$, node $\mathrm{i}$ joins the cascade and becomes a susceptible node (potential innovation adopter), suggesting $v_{i}(t)=1$. The cascade process of node $a_{i j}$ is specified as follows:

Step 1: Assign a threshold $d_{i}$ for each node based on a given probability distribution function $f\left(d_{i}\right)$;

Step 2: Set most nodes to be in a normal state at the beginning, meaning $v_{i}(0)=0, \forall i$. Some adoption nodes with a ratio of $S(0)$ are set as seed nodes, which triggers cascade dynamics, where $S$ represents the cascading scale;

Step 3: The state of the nodes is updated according to the following decision rules

$$
v_{i}(t)=\left\{\begin{array}{c}
1, \quad \text { if } \frac{1}{k_{i}} \sum_{j} a_{i j} v_{j}(t)>d_{i}, \\
0, \quad \text { or }
\end{array}\right.
$$

where $a_{i j}$ stands for the $j$ th neighbor of node $a_{i}$ and $k_{i}$ is the degree of node $i$;

Step 4: Repeat step 3 until a node reaches a stable state, at which the node density is added to the cascading scale $s$ and is calculated by $S=\frac{1}{n} \sum_{i=1}^{n} v_{i}(t)$.

\subsection{Model establishment}

The purpose of this model is to provide an experimentation platform to gain insights into the cascade effect in collaborative innovation in the context of construction projects. There can be $n$ individuals (nodes) in a project network. The connection reflects the relations of the individuals participating in innovation tasks, executing the same task or relating to the task, which is measured by degree $k$ in the model. $S_{k}(t)$ represents the proportion of individuals who are taking part in collaborative innovation among $k$ individuals connected to each of them at time $t$. The probability of each node connecting to its $k$ neighboring nodes in the network is $P(k) \cdot \frac{k P(k)}{k}$ represents the preference probability of individuals with any connection to degree $k . k=\sum_{k \geq 1} k P(k)$ shows the average network degree. At time $t$, the probability that a node with an in-degree of $k$ has an edge (link) pointing to the innovation entity is

$$
\Theta(t)=\frac{1}{k} \sum_{k} k P(k) S_{k}(t) .
$$

At time $t$, any individual has $k$ neighbors, and the probability that there are $a(a \leq k)$ adopters in the neighborhood is defined by as binomial distribution as below:

$$
B(k, a)=C_{k}^{a} \Theta(t)^{a}(1-\Theta(t))^{k-a} .
$$

According to the classical theory regarding the threshold mechanism for collective behaviors, if an individual behaves differently from a few people around them, the individual does not feel any social pressure to conform. However, once that number of people reaches a certain point, the individual is under great pressure and starts to imitate the behaviors of the majority. In the process of innovative decisions, the number $(a)$ of neighbors affects the innovation decisions of an innovation adopter. $F(k, a)$ represents the interactive mechanism between subjects, depicts the mode and extent of interdependence among individuals in decision-making, and indicates the proportion of internal preference and external coordination in decision-making. In other words, $F(k, a)$ specifies the decision-making behavior of individuals (actors) and the status in the project network. Decision threshold rules can be described as

$$
F(k, a)=\left\{\begin{array}{l}
1, \frac{a}{k}>d \\
0, \frac{a}{k} \leq d
\end{array},\right.
$$

where $0<d \leq 1$ and the smaller the number, the higher the sensitivity of an individual to outside influences.

Considering stakeholder interactions, the probability of individuals joining the collaborative innovation cascade is set as

$$
R(a \mid k, \Theta(t))=\sum_{a=0}^{k} C_{k}^{a} \Theta(t)^{a}(1-\Theta(t))^{(k-a)} F(k, a) .
$$

The proportion of adopters in the network is obtained by the mean-field theory (Granovetter,1978):

$$
\frac{d s_{k}(t)}{d(t)}=\left(1-S_{k}(t)\right) \sum_{a=0}^{k} C_{k}^{a} \Theta(t)^{a}(1-\Theta(t))^{(k-a)} F(k, a) \text {. }
$$

The network reaches a stable state when node states do not change, or $\frac{d S_{k}(t)}{d t}=0$. The cascading scale is specified as

$$
S=\sum_{k} P(k) S_{k},
$$

where $S$ represents the proportion of individuals participating in collaborative innovation.

\section{Simulation experiments and findings}

Dynamics in terms of cascade scale or speed were simulated under different network structures by varying network type, size, average degree, and initial adopter attributes (number and role of innovation adopters) to identify the key factors influencing the cascade effect of collaborative innovation in infrastructure projects.

The project network structure is affected by the contracting methods of the projects because the contractual provisions dictate stakeholders' relationships and roles. The typical contracting methods seen in practices include Design-Bid-Build, Construction Management (CM), De- 
sign-Build (DB), Public-Private Partnership (PPP), and so on. $\mathrm{CM}$ and $\mathrm{DB}$ are the most widely used cooperative contracting methods in infrastructure projects in practice (Zhang et al., 2018). DB is often used in mega-projects to encourage collaboration and innovation. The typical contractual relationships of $\mathrm{CM}$ and $\mathrm{DB}$ among stakeholders are shown in Figures 4 and 5.

Figure 4 suggests that the relationship among stakeholders in a CM project is hierarchical, there are many connections between individuals at two levels, and the clustering coefficient is low. Therefore, the CM project network can be approximately regarded as a generic network. The average network degree is $\bar{k}$, meaning that each individual connects $\bar{k}$ subordinate organization nodes on average. As a result, the total number of edges (links) in the CM project network is $N \bar{k}$.

The relationship among stakeholders in a $\mathrm{DB}$ project appears as a pyramidal shape (see Figure 5). All organization nodes at other levels are subject to only one parent (the top level) node. Supposing the management scope of the top level is $D$, then the out-degree of every node is $D$ in the DB project network except for the lowest level nodes. So, the average degree of the DB project network is $\frac{(N-n) \cdot D}{N}$, where $n$ is the number of the lowest level nodes in the network.

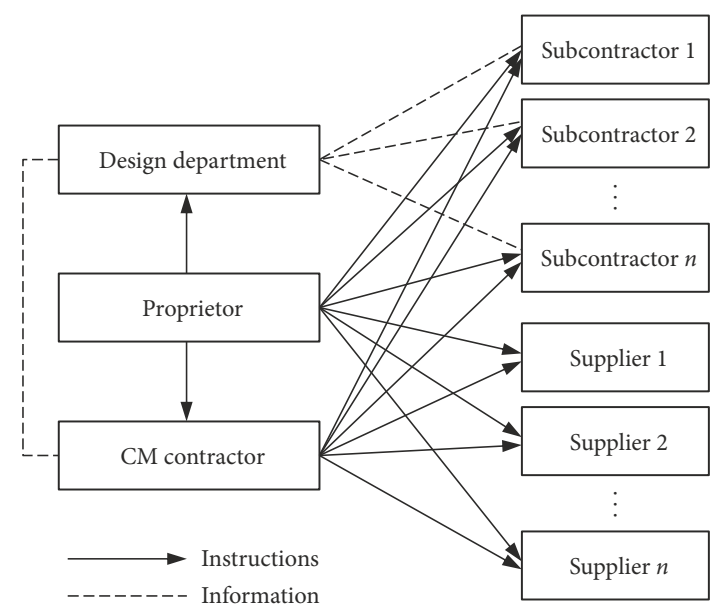

Figure 4. Relationship among stakeholders of a CM project

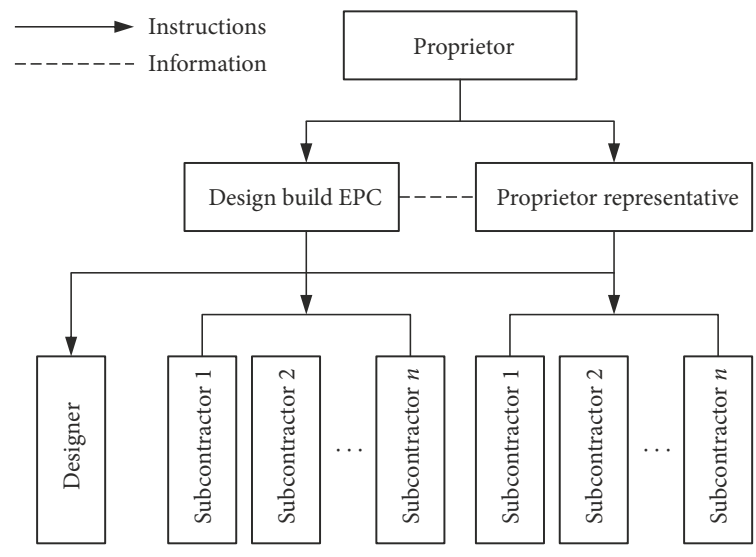

Figure 5. Relationship among stakeholders of a DB project

\subsection{Sensitivity of network types}

This study assumed that the structures of CM and DB networks are different, so the cascade effects were simulated in the two networks. It was further assumed that 500 individuals belong to different organizations in project teams, such as general contractors, suppliers, subcontractors, architects, consultants, engineers, and clients. The total number of nodes in the simulation was $N=500$. Each individual node is connected to four individuals on average, i.e., $\langle k>=4$. The number of initial innovation adopters in the project networks is set equal to $k=\frac{1}{N} \sum_{i=1}^{N} k_{i}$ and the proportion of initial adopters was set to 0.01 . Five individuals were randomly selected as seed nodes. The value $d$ was initialized and generated in a standard normal distribution.

A simulation ran for 200-time steps, and it was iterated 50 times for each setting. The cascade effect of collaborative innovation was significantly different in the two different networks. The cascade scale and threshold $d_{i}$ are monotonically decreasing in the CM network (see Figure 6). In the DB network, with the increase of $d_{i}$, the cascade scale also decreases in Figure 7. In this gradient descent process, $S$ does not decrease immediately with the increase of $d$, but will remain unchanged $(S=93 \%)$ within a certain range of values $(d=0 \sim 0.12)$. When $\mathrm{d}$ exceeds 0.12 , the $S$ value drops to $80 \%$ and then remains constant until the $\mathrm{d}$ value increases to 0.24 . However, no homogeneity is shown in the CM network, which mainly shows a monotonic decrease. Compared with the DB network, the $\mathrm{CM}$ network shows heterogeneity, suggesting that network heterogeneity alters the tendency to decrease.

The negative correlation between cascade scale and threshold $d_{i}$ shows that an individual innovation adopter is often sensitive to external influences. Figures 6 and 7 reveal that a large threshold value of $d_{i}$ leads to a small $S$, suggesting that an individual is not easily influenced by other adjacent individuals. Nevertheless, small cascading scale $(S)$ of a project network implies that it is more sensitive to external influences and more likely to adopt innovation. Hence, the cascade effect of collaborative innovation in infrastructure projects is sensitive to network type and this affects the cascade scale at stable state. In other words, contracting methods affect the speed and scope of the collaborative innovation cascade.

The individuals in a decentralized parallel contracting method (DB) are not particularly sensitive to external influences, while individuals under the CM contracting arrangement are more susceptible to external influences and are more likely to be influenced when making decisions. This suggests that in organizational environments of engineering project networks, the DB model is not as effective as $\mathrm{CM}$ in advancing collaborative innovation because the latter can take advantage of the network and agilely influence individual decision-making by changing the network environment, thereby promoting the collaboration of all entities in innovation. 


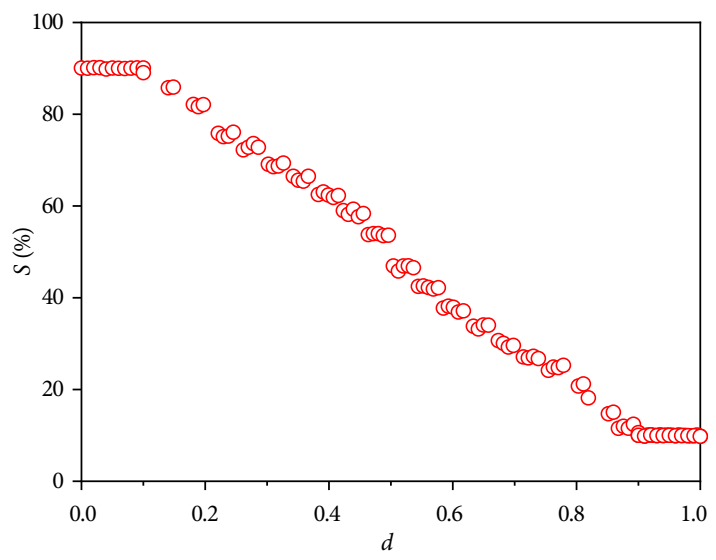

Figure 6. Cascade scale and threshold value $d$ in the CM project network

\subsection{Sensitivity of network structure}

Network structures are evaluated according to statistical indicators in a network, like network size (number of nodes) and average degree (number of edges or links). Owing to the close relationship between individuals in the CM project, individuals (nodes) at different levels are connected based on instructions or shared information in the project network, which presents structural heterogenization. Herein, the size and average degree of the CM network were varied in each run in the simulation in order to reveal various cascade processes.

Network size is determined by the number of stakeholders in the project network. The number of nodes $N$ was set to $100,200,500$, and 1000 to simulate various cascade processes. The ratio of initial adopters, 0.1 , was randomly selected by the system. If it is supposed that an individual is around more than three innovation adopters, the individual also adopts the innovation. Then, the threshold $d_{i}$ is set to 3 . Figure 8 shows simulation results based on the settings. There is no significant difference in cascade scales at different network sizes when the network reaches a stable state. The cascade scale reached $97 \%$ when the networks of different sizes reached a stable state. This suggests that network size has a negligible influence on cascade scale. At the same time, it takes longer for the cascade of larger networks to reach a stable state. For instance, when network size was 100 , the cascade reached a stable state at $t=47$; when the network size was 200 , the cascade stabilized at $t=59$. Therefore, cascade speed is negatively correlated with network size and the cascade scale of collaborative innovation is insensitive to network size.

The scale of a project affects the speed of collaborative innovation. The larger the project, the longer it takes to realize effective collaborative innovation. Compared with typical projects, mega infrastructure projects tend to involve more participants. It takes time for a huge temporary organization team to reach a stable state of collaborative innovation. Therefore, it is important to minimize redundant institutions and rely on the core organization in collaborative innovation.

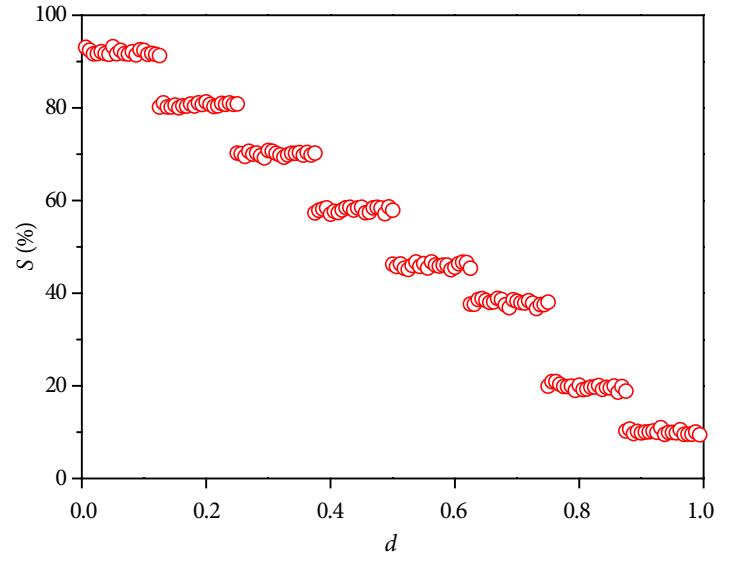

Figure 7. Cascade scale and threshold value $d$ in the DB project network

The number of nodes directly connecting to a specific node is a measure of network degree. Paths between any two nodes are positively correlated with the number of connections in a network. Repeated interactions can enhance trust between actors (nodes), which may substantially improve the quality of exchange and the outcome of the interactions (Powell, 1990). This study varied the average degree of the networks in order to simulate various cascade effects. The average degree of the CM network was set to $k=2 m, m=2,4,8$. The ratio of the initial adopter, 0.1 , was randomly selected by the system. The threshold value $d_{i}$ was set to 3 .

Figure 9 presents the cascade effect for different average network degrees, showing that this has a significant impact on the cascade at the initial stages. When $t$ is between 0 and $20,\langle k\rangle=16$ resulted in the largest cascade scale, followed by $\langle k\rangle=8 ;\langle k\rangle=4$ led to the smallest cascade scale. The difference in cascade scale among the three networks expanded between $t=20$ and $t=60$. The results show that networks with higher average degrees have larger cascade scales in the early stages, meaning that high average network degree increases the instantaneous speed of the cascade in a specific timeframe. However, the overall cascade takes more time $(t=78)$ to reach the stable state when the average network degree is 4 , while networks with a high average degree stabilize relatively quickly. For instance, when $\langle k\rangle=16$ the cascade reached a stable state at $t=75$. Further, the cascade scales of these three networks were nearly identical $(S(100)=96 \%)$ when the cascade reached a steady state.

Therefore, it can be concluded that the cascade effect of collaborative innovation in project networks is sensitive to the average degree of the network within a certain time range. Close network connections accelerate the cascade speed of collaborative innovation. The density of networks has a minor effect on the cascade scale of collaborative innovation at steady state. In real-world contexts, the closer the connections between the organizations involved in a project, the better for collaborative innovation. Therefore, it is necessary to pay close attention to the relationship between individuals, teams, and organizations. It is also 


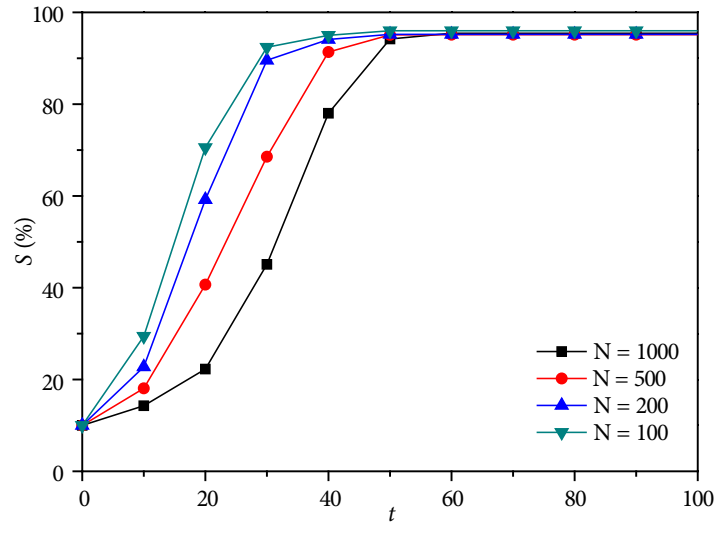

Figure 8. Cascade effect is influenced by the network size

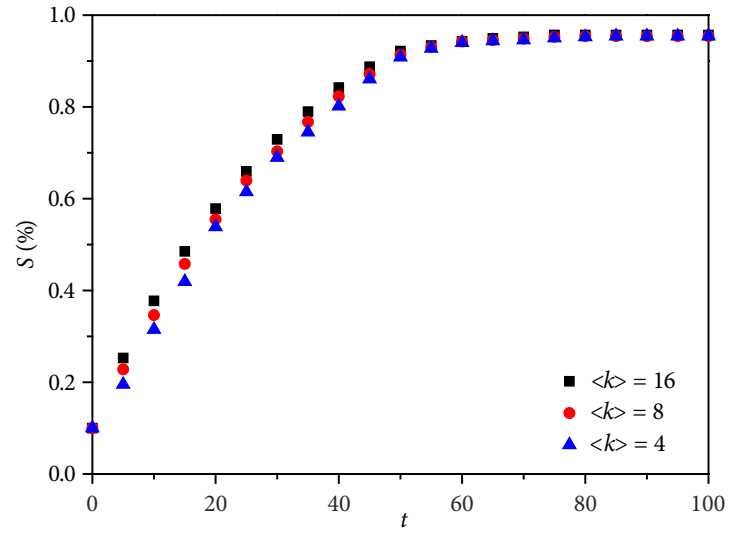

Figure 9. Cascade effect is influenced by average degree important to strengthen the communication between the same team of different departments at different levels, so as to build a close organizational network and accelerate collaborative innovation.

\subsection{Sensitivity to the number of initial adopters}

Initial adopters can be viewed as the factor which triggers the cascade effect. Given that the characteristics of initial adopters affects the scale and speed of the cascade, the simulations in this study varied the number of initial adopters in the network in order to demonstrate various cascade processes. Five different DB project networks were simulated with the proportion of initial adopters at $S(0)=$ $0.03, S(0)=0.05, S(0)=0.02, S(0)=0.10$, and $S(0)=0.20$. Simulations were carried out for 50 projects based on each of the cascade effect variants in the abovementioned project networks, in which the average values were used to offset the effect of randomness on the cascade processes. For each simulation, the same configuration was used, e.g., $N=500, d_{i}=3$. The results are shown in Figure 10 .

The simulation results reveal that the cascade scale expands as $S(0)$ increases. When $S(0) \geq 0.10$, an approximately full cascading can be achieved in the network. For instance, when $S(0)=0.10, S(100)=95.13 \%$; when $S(0)=$ $0.20, S(100)=97.05 \%$. According to the overall trend, increasing the number of initial adopters shortens the time for cascades to reach stable states and improves the cascade scale within each step length.

It is concluded from the above analysis that the cascade scale of collaborative innovation in project networks is sensitive to the number of initial innovation adopters. Furthermore, a large number of adopters at early stages tends to lead to more individuals adopting an innovation in the project network. In practice, infrastructure projects often innovate due to the complexity and variability of construction conditions. In order to achieve better innovation, project leaders should take innovation capabilities and experience as important criteria when choosing partners, attempt to get more innovation adopters to influence the team, and encourage other organizations to be part of the innovation, so that the collaborative innovation of the entire project team occurs at a faster rate with better results.

\subsection{Sensitivity to the role of initial adopters}

In collaborative innovation, individuals with different job titles in the project network play different roles (Xue et al., 2018). This study assumed three formal organizational roles for initial adopters (the general contractor, subcontractor, and other randomly assigned roles), and set the number of initial adopters $S(0)=0.05$. The simulation was implemented 50 times in a DB network and a CM network, respectively, and the average s values were recorded to reduce deviations caused by randomness.

Figure 11 illustrates the results of these simulations, in which "random" represents the randomly assigned role for an initial adopter; "top-down" denotes the initial adopter assuming the role of owner in the CM network or general contractor in the DB network; and "grassroots" represents the initial adopters as subcontractors. Figure 11 suggests that the time taken for cascades to reach stable states depends on the different initial adopter roles which were assumed.

When the initial innovation adopter is randomly assigned as owner/general contractor, the time to reach a stable state in the CM network is shorter than that in the $\mathrm{DB}$ network ( $t=48$ in $\mathrm{DB}, t=27$ in $\mathrm{CM})$. However, the time for the two networks to reach a stable state was similar when the initial innovation adopter was assumed to be a subcontractor ( $t=27$ in $\mathrm{DB}, t=26$ in CM). Accordingly, the number of individuals connected to the initial innovation adopters impacts the cascade scale because the owner in the CM network and general contractor in the DB network typically locate at the center of the networks, which puts them at an advantageous position to reach other actors (stakeholders). Hence, when the key individuals in a construction project are designated as initial innovation adopters, this can accelerate the cascade speed of collaborative innovation in a project network.

The cascade scale of collaborative innovation is sensitive to the role of the initial innovation adopters, and the position of the initial adopters in the network can greatly affect the cascade effect of collaborative innovation in an infrastructure project. In reality, support for project innovation from the top management is critical to the spread of innovation activities because the top management has 


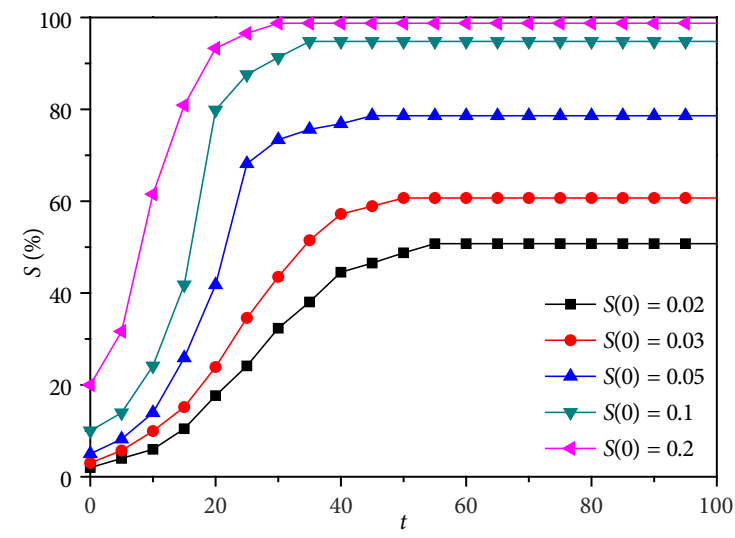

Figure 10. Cascade effect is influenced by the number of initial adopters

substantive influence on individuals involved in a project and possesses more control and power on resources for collaborative innovation. Therefore, it is critical to strengthen the innovation awareness of the core organizations and promote individuals who are forward-looking and open to new things as core management personnel.

\section{Validation}

The goal of validating a simulation model is to ensure that the model can maintain consistent accuracy within an acceptable range of intended model applications (Schlesinger, 1979). A balance between model realism and model relevance to the research scope and question should be struck (Burton \& Obel, 1995). Insufficient realism would undermine the generalizability of the results, but too much realism could lead to difficulties in terms of interpreting and analyzing the results (Axelrod, 1997). For this reason, the assumptions of the model were simplified without jeopardizing its ability to answer the research question concerning what affects the behavior cascade of collaborative innovation in infrastructure projects.

As a popular research method, simulation has tended to be used in construction contexts to assist decisionmaking processes and serve as a decision-making support tool. By contrast, this research attempts to gain insights into the behavior cascade of the decision-making of innovation adoption in infrastructure projects. Hence, the validation process of this research is less dependent on expert opinions, empirical data, and case studies, that are important for discrete event simulation (Chinowsky et al., 2011; Taylor et al., 2009; Unsal \& Taylor, 2011). Instead, the focus is more on the extent to which the simulation resembles the collaborative innovation processes in infrastructure projects. Hence, the simulation parameters were set in accordance with real practices in infrastructure project innovation, which entails multi-party collaboration and interactions. To demonstrate the behavior cascade of collaborative innovation in infrastructure projects, the simulation was grounded in two established theories: the cooperative behavior cascade (Fowler \& Christakis, 2010) and the SIR model (Kermark \& McKendrick, 1927).

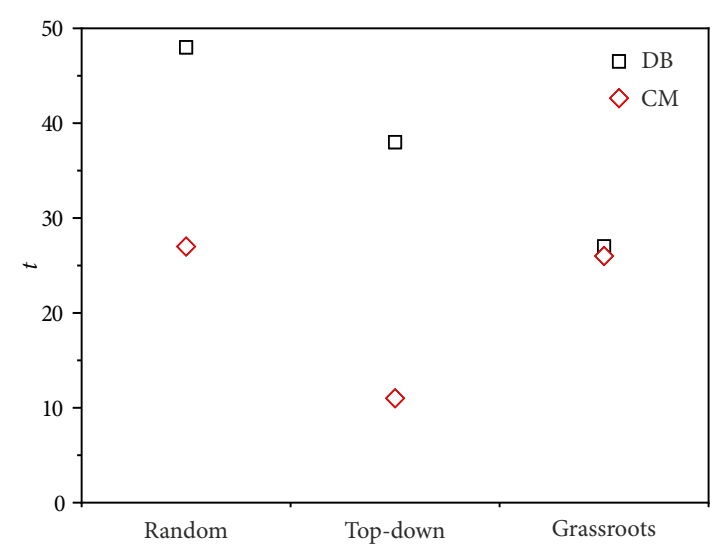

Figure 11. Cascade effect is influenced by the role of adopter

\section{Conclusions}

Collaborative innovation has been emphasized pursuant to achieving sustainability and efficiency in construction projects. However, compared with other industries, construction involves multiple heterogenous participants and collaborations are more complex due to high fragmentation and uniqueness of each individual project. This paper puts forward a new perspective on collaborative innovation showing how the innovation process evolves in construction project networks. Previous research has shown that the mimicry mechanism is the main cause of the cascade of cooperative behaviors, spreading from person to person to person. Such a mechanism suggests that network relationships between individuals can drive the evolution of collaborative innovation. The simulation in this research attempts to demonstrate the impacts of the cascade effect of collaborative infrastructure innovation and the evolution of the behavior cascade under various realistic scenarios.

The experimental results show that the threshold value of initial innovation adopters is negatively correlated with cascade scale, and network type can change the patterns of their relationships. It is also revealed that the cascade effect of collaborative innovation in infrastructure projects is sensitive to network structure (e.g., network scales and average degrees). The number and role of initial innovation adopters play an important role in the cascade effect of collaborative innovation and are positively correlated with the cascade effect. These findings have significant practical implications for infrastructure projects in innovation management.

This paper offers a novel network science perspective on collaborative innovation in infrastructure projects to study the influence of network attributes on decisions concerning innovation adoption. The simulation model reinforces current theories in the context of collaborative project innovation networks. The results revealed that stakeholder decisions are critical to understand innovation practices and decisions, which lead to their adoption in the project network. Furthermore, the simulation demonstrates that network structure can accelerate or moder- 
ate the cascades of cooperative behavior in project networks. The results provide input into an ongoing debate in the literature on project networks regarding construction innovation performance. The results of the research also suggest important strategic considerations for construction innovation. Recognizing the existence of dynamics behind individuals' interactions, managers can exploit incentive mechanisms to build more efficient project networks.

Nevertheless, the applicability of the model in its current form is limited to answering our research question. Specifically, one assumption of the model is that a project network focuses on only one project phase. Therefore, future research should investigate dynamic project networks to shed light on the interaction mechanisms among stakeholders and provide a better understanding of collaborative innovation in different phases of infrastructure projects. Another limitation concerns the project networks used in the simulation. This research explored two such networks (i.e., DB and CM networks) as the simulation environment. These networks have distinct characteristics but many project networks do not strictly follow typical contractual relationships. Accordingly, future research could seek to provide effective methods for portfolio project networks, which may be more useful to guide practices in collaborative innovation management.

\section{Acknowledgements}

This research was financially supported by the National Natural Science Foundation of China (NSFC) (Grant No.71801119, 71901077, and 71671053), the Major Programs of National Social Science Foundation (Grant No. 18ZDA043), Liaoning's Economic and Social Development Foundation (Grant No. 20211slqnkt-019), and the Social Science Planning Foundation of Liaoning Province (Grant No. L20BGL031).

\section{References}

Abrahamson, E., \& Rosenkopf, L. (1997). Social network effects on the extent of innovation diffusion: a computer simulation. Organization Science, 8(3), 289-309.

https://doi.org/10.1287/orsc.8.3.289

Axelrod, R. (1997). Advancing the art of simulation in the social sciences. Complexity, 3(2), 21-40.

https://doi.org/10.1002/(SICI)1099-0526(199711/12)3:2<16:: AID-CPLX4>3.0.CO;2-K

Baiden, B. K., Price, A. D., \& Dainty, A. R. (2006). The extent of team integration within construction projects. International Journal of Project Management, 24(1), 13-23. https://doi.org/10.1016/j.ijproman.2005.05.001

Baldwin, C. Y., \& Von Hippel, E. A. (2011). Modeling a paradigm shift: from producer innovation to user and open collaborative innovation. Social Science Electronic Publishing, 22(6), 1399-1417. https://doi.org/10.2139/ssrn.1502864

Bertelsen, S. (2003). Construction as a complex system [Conference presentation]. $11^{\text {th }}$ Annual Meeting of the Int. Group for Lean Construction, Lean Construction Institute, La Jolla, CA. Bhaskarabhatla, A., \& Hegde, D. (2014). An organizational per- spective on patenting and open innovation. Organization Science, 26(6), 1744-1763.

https://doi.org/10.1287/orsc.2014.0911

Bikhchandani, S., Hirshleifer, D., \& Welch, I. (1992). A theory of fads, fashion, custom and cultural change as Informational cascades. Journal of Political Economy, 100(5), 992-1026. https://doi.org/10.1086/261849

Bond, R. M. (2019). Low-cost, high-impact altruistic punishment promotes cooperation cascades in human social networks. Scientific Reports, 9(1), 2061.

https://doi.org/10.1038/s41598-018-38323-7

Bossink, B. (2007). The interorganizational innovation processes of sustainable building: A Dutch case of joint building innovation in sustainability. Building and Environment, 42(12), 4086-4092. https://doi.org/10.1016/j.buildenv.2006.11.020

Bossink, B. A. (2004). Managing drivers of innovation in construction networks. Journal of Construction Engineering and Management, 130(3), 337-345.

https://doi.org/10.1061/(ASCE)0733-9364(2004)130:3(337)

Borgatti, S. P., \& Foster, P. C. (2003). The network paradigm in organizational research: a review and typology. Journal of Management, 29(6), 991-1013.

https://doi.org/10.1016/S0149-2063(03)00087-4

Brass, D. J., Galaskiewicz, J., Greve, H. R., \& Tsai, W. (2004). Taking stock of networks and organizations: a multilevel perspective. Academy of Management Journal, 47(6), 795-817. https://doi.org/10.2307/20159624

Burton, R. M., \& Obel, B. (1995). The validity of computational models in organization science: From model realism to purpose of the model. Computational \& Mathematical Organization Theory, 1(1), 57-71. https://doi.org/10.1007/BF01307828

Calamel, L., Defélix, C., Picq, T., \& Retour, D. (2012). Interorganisational projects in French innovation clusters: the construction of collaboration. International Journal Project Management, 30(1), 48-54.

https://doi.org/10.1016/j.ijproman.2011.03.001

Chesbrough, H. W. (2006). Open business models: how to thrive in the new innovation landscape. Harvard Business School Publishing.

Chinowsky, P., Taylor, J. E., Marco, M. D. (2011). Project network interdependency alignment: new approach to assessing project effectiveness. Journal of Management in Engineering, 27(3), 170-178.

https://doi.org/10.1061/(ASCE)ME.1943-5479.0000048

Collins, R. (2004). Interaction ritual chains. Princeton: Princeton University Press. https://doi.org/10.1515/9781400851744

Cornick, T., \& Mather, J. (1999). Construction project teams: making them work profitably. Thomas Telford. https://doi.org/10.1680/cptmtwp.27459

Enquist, M., \& Leimar, O. (1993). The evolution of cooperation in mobile organisms. Animal Behaviour, 45(4), 747-757. https://doi.org/10.1006/anbe.1993.1089

Fehr, E., \& Fischbacher, U. (2004). Social norms and human cooperation. Trends in Cognitive Sciences, 8(4), 185-190. https://doi.org/10.1016/j.tics.2004.02.007

Fischer, S. (1992). America calling: A social history of the telephone to 1940. University of California Press.

Fowler, J. H., \& Christakis, N. A. (2010). Cooperative behavior cascades in human social networks. Proceedings of the $\mathrm{Na}$ tional Academy of Sciences, 107(12), 5334-5338. https://doi.org/10.1073/pnas.0913149107

Girmscheid, G., \& Rinas, T. (2012). Business design modeling for industrialization in construction: cooperative approach. Journal of Architectural Engineering, 18(2), 164-167. https://doi.org/10.1061/(ASCE)AE.1943-5568.0000089 
Granovetter, M. (1978). Threshold models of collective behavior. The American Journal of Sociology, 83(6), 1420-1443. https://doi.org/10.1086/226707

Hallegatte, S., Rentschler, J., \& Rozenberg, J. (2019). Lifelines: The resilient infrastructure opportunity. The World Bank. https://doi.org/10.1596/978-1-4648-1430-3

Han, Y., Li, Y., Taylor, J. E., \& Zhong, J. (2018). Characteristics and evolution of innovative collaboration networks in architecture, engineering, and construction: study of national prize-winning projects in China. Journal of Construction Engineering and Management, 144(6), 04018038.1-04018038.11. https://doi.org/10.1061/(ASCE)CO.1943-7862.0001499

Hanaki, N., Peterhansl, A., Dodds, P. S., \& Watts, D. J. (2007). Cooperation in evolving social networks. Management Science, 53(7), 1036-1050. https://doi.org/10.1287/mnsc.1060.0625

Herrera, R. F., Mourgues, C., Alarcón, L. F., \& Pellicer, E. (2020). Understanding interactions between design team members of construction projects using social network analysis. Journal of Construction Engineering and Management, 146(6), 04020053. https://doi.org/10.1061/(ASCE)CO.1943-7862.0001841

Holmen, E., Pedersen, A. C., \& Torvatn, T. (2005). Building relationships for technological innovation. Journal of Business Research, 58(9), 1240-1250. https://doi.org/10.1016/j.jbusres.2003.10.010

Hong, S., Lv, C., Zhao, T., Wang, B., Wang, J., \& Zhu, J. (2016). Cascading failure analysis and restoration strategy in an interdependent network. Journal of Physics A: Mathematical and Theoretical, 49(19), 195101.

https://doi.org/10.1088/1751-8113/49/19/195101

Hong, S., Zhu, J., Braunstein, L. A., Zhao, T., \& You, Q. (2017). Cascading failure and recovery of spatially interdependent networks. Journal of Statistical Mechanics: Theory and Experiment, 103208. https://doi.org/10.1088/1742-5468/aa8c36

Hossain, L. (2009). Effect of organizational position and network centrality on project coordination. International Journal of Project Management, 27(7), 680-689.

https://doi.org/10.1016/j.ijproman.2008.11.004

Jackson, M.O., Watts, A. (2002). The evolution of social and economic networks. Journal of Economic Theory, 106(2), 265295. https://doi.org/10.1006/jeth.2001.2903

Kapsali, M. (2011). Systems thinking in innovation project management: a match that works. International Journal of Project Management, 29(4), 396-407.

https://doi.org/10.1016/j.ijproman.2011.01.003

Kearns, M., Suri, S., \& Montfort, N. (2006). An experimental study of the coloring problem on human subject networks. Science, 313, 824-827.

https://doi.org/10.1126/science.1127207

Kearns, M., Judd, S., Tan, J., \& Wortman, J. (2009). Behavioral experiments on biased voting in networks. Proceedings of the National Academy of Sciences, 106(5), 1347-1352.

https://doi.org/10.1073/pnas.0808147106

Kermark, M., McKendrick, A.G. (1927). Contributions to the mathematical theory of epidemics. Proceedings of the Royal Society A Mathematical Physical \& Engineering Sciences, 115, 700-721. https://doi.org/10.1098/rspa.1927.0118

Kilduff, M., \& Tsai, W. (2003). Social networks and organizations. Sage. https://doi.org/10.4135/9781849209915

Klovdahl, A. S. (1985). Social networks and the spread of infectious diseases: The AIDS example. Social Science \& Medicine, 11(21), 1203-1216.

https://doi.org/10.1016/0277-9536(85)90269-2

Law, G. D. (2010). Network project management visualising collective knowledge to better understand and model a projectportfolio. University of Canberra, Australia.
Lee, C. Y., Chong, H. Y., Liao, P. C., \& Wang, X. (2018). Critical review of social network analysis applications in complex project management. Journal of Management in Engineering, 34(2), 04017061.

https://doi.org/10.1061/(ASCE)ME.1943-5479.0000579

Lin, S. C. (2015). An analysis for construction engineering networks. Journal of Construction Engineering and Management, 141(5), 04014096.

https://doi.org/10.1061/(ASCE)CO.1943-7862.0000956

Liu, L., Han, C., \& Xu, W. (2015). Evolutionary analysis of the collaboration networks within National Quality Award Projects of China. International Journal of Project Management, 33(3), 599-609. https://doi.org/10.1016/j.ijproman.2014.11.003

Loosemore, M. (1997). Construction crises as periods of social adjustment. Journal of Management in Engineering, 13(4), 3037. https://doi.org/10.1061/(ASCE)0742-597X(1997)13:4(30)

Loosemore, M. (1998). Social network analysis: using a quantitative tool within an interpretative context to explore the management of construction crises. Engineering Construction and Architectural Management, 5(4), 315-326.

https://doi.org/10.1046/j.1365-232X.1998.54039.x

Loosemore, M. (2015). Construction innovation: Fifth generation perspective. Journal of Management in Engineering, 31(6), 04015012.

https://doi.org/10.1061/(ASCE)ME.1943-5479.0000368

Lu, Y., Li, Y., Skibniewski, M., Wu, Z., Wang, R., \& Le, Y. (2015). Information and communication technology applications in architecture, engineering, and construction organizations: A 15-year review. Journal of Management in Engineering, 31(1), A4014010.

https://doi.org/10.1061/(ASCE)ME.1943-5479.0000319

Markus, M. L. (1987). Toward a "critical mass" theory of interactive media: Universal access, interdependence and diffusion. Communication Research, 14(5), 491-511. https://doi.org/10.1177/009365087014005003

Mead, S. P. (2001). Using social network analysis to visualize project teams. Project Management, 32(4), 32-38.

https://doi.org/10.1177/875697280103200405

Moreno, J. L. (1960). The sociometry reader. The Free Press, Glencore, III.

Nowak, M. A. (2012). Evolving cooperation. Journal of Theoretical Biology, 299, 1-8. https://doi.org/10.1016/j.jtbi.2012.01.014

Ohtsuki, H., Hauert, C., Lieberman, E., \& Nowak, M. A. (2006). A simple rule for the evolution of cooperation on graphs and social networks. Nature, 441, 502-505.

https://doi.org/10.1038/nature04605

Powell, W. W., Koput, K. W., \& Smithdoerr, L. (1996). Interorganizational collaboration and the locus of innovation: networks of learning in biotechnology. Administrative Science Quarterly, 41(1), 116-145. https://doi.org/10.2307/2393988

Powell, W. W. (1990). Neither market nor hierarchy: network forms of organization. Research in Organizational Behavior, 12, 295-336.

Pryke, S. D. (2004). Analyzing construction project coalitions: exploring the application of social network analysis. Construction Management and Economics, 22, 787-797. https://doi.org/10.1080/0144619042000206533

Rutten, M. E. J., Dorée, A. G., \& Halman, J. I. M. (2009). Innovation and interorganizational cooperation: a synthesis of literature. Construction Innovation, 9(3), 285-297. https://doi.org/10.1108/14714170910973501

Sandhu, M., \& Helo, P. (2006). Network approach to project business analysis. Engineering, Construction and Architectural Management, 213(6), 600-615. https://doi.org/10.1108/09699980610712391 
Santos, F. C., Santos, M. D., \& Pacheco, J. M. (2008). Social diversity promotes the emergence of cooperation in public goods games. Nature, 454, 213-216. https://doi.org/10.1038/nature06940

Schlesinger, S. (1979). Terminology for model credibility. Simulation, 32(3), 103-104. https://doi.org/10.1177/003754977903200304

Serrano, V., \& Fischer, T. (2007). Collaborative innovation in ubiquitous systems. Journal of Intelligent Manufacturing, 18, 599-615. https://doi.org/10.1007/s10845-007-0064-2

Skyrms, B., \& Pemantle, R. (2000). A dynamic model of social network formation. Proceedings of the National Academy of Sciences of the United States of America, 97(16), 9340-9346. https://doi.org/10.1073/pnas.97.16.9340

Son, J., \& Rojas, E. M. (2009). Understanding collaborative working processes of temporary project teams in large-scale construction projects. In Construction Research Congress 2009 (pp. 856-865). https://doi.org/10.1061/41020(339)87

Son, J. W, \& Rojas, E. M. (2011). Evolution of collaboration in temporary project teams: An agent-based modeling and simulation approach, Journal of Construction Engineering and Management, 137(8), 619-628.

https://doi.org/10.1061/(ASCE)CO.1943-7862.0000331

Stinchcombe, A. L. (1959). Bureaucratic and craft administration of production: a comparative study. Administrative Science Quarterly, 4(2), 168-187. https://doi.org/10.2307/2390676

Taylor, J. E., \& Levitt, R. (2007). Innovation alignment and project network dynamics: an integrative model for change. Project Management Journal, 38(3), 22-35. https://doi.org/10.1002/pmj.20003

Taylor, J. E., Levitt, R., \& Villarroel, J. A. (2009). Simulating learning dynamics in project networks. Journal of Construction Engineering and Management, 135(10), 1009-1015. https://doi.org/10.1061/(ASCE)CO.1943-7862.0000065

Tichy, N. M., Tushman, M. L., \& Fombrun, C. (1979). Social network analysis for organizations. The Academy of Management Review, 4(4), 507-519. https://doi.org/10.5465/amr.1979.4498309

Turner, J. R., \& Müller, R. (2003). On the nature of the project as a temporary organization. International Journal of Project Management, 21(1), 1-8. https://doi.org/10.1016/S0263-7863(02)00020-0

Unsal, H. I., \& Taylor, J. E. (2011). Modeling interfirm dependency: Game theoretic simulation to examine the holdup problem in project networks. Journal of Construction Engineering and Management, 137(4), 284-293. https://doi.org/10.1061/(ASCE)CO.1943-7862.0000286

Van Duijn, M. A. J., \& Vermunt, J. K. (2006). What is special about social network analysis? Methodology: European Journal of Research Methods for the Behavioral and Social Sciences, 2(1), 2-6. https://doi.org/10.1027/1614-2241.2.1.2

Vespignani, A. (2009). Predicting the behavior of techno-social systems. Science, 325, 425-428. https://doi.org/10.1126/science. 1171990

Watts, D. J., \& Strogatz, H. S. (1998). Collective dynamics of 'small-world' networks. Nature, 393, 440-442. https://doi.org/10.1038/30918

Weber, J. M., \& Murnighan, J. K. (2008). Suckers or saviors? Consistent contributors in social dilemmas. Journal of Personality and Social Psychology, 95(6), 1340-1353. https://doi.org/10.1037/a0012454

Welch, I. (1992). Sequential sales, learning, and cascades. Journal of Finance, 47(2), 695-732. https://doi.org/10.2307/2329120
Xue, X., Zhang, R.X., Wang, L., Fan H. Q., Yang, R. J., \& Dai, J. (2018). Collaborative innovation in construction project: a social network perspective. KSCE Journal of Civil Engineering, 22(2), 417-427. https://doi.org/10.1007/s12205-017-1342-y

Yepes, V., Pellicer, E., Alarcón, L. F., \& Correa, C. L. (2016). Creative innovation in Spanish construction firms. Journal of Professional Issues in Engineering Education and Practice, 142(1), 04015006. https://doi.org/10.1061/(asce)ei.1943-5541.0000251

Zhang, Y., Chini, A., Minchin Jr, R. E., Ptschelinzew, L., \& Shah, D. (2018). Performance of seven highway construction contracting methods analyzed by project size. Frontiers of Engineering Management, 5(2), 240-250. https://doi.org/10.15302/J-FEM-2018040

Zhu, J., \& Mostafavi, A. (2017). Metanetwork framework for integrated performance assessment under uncertainty in construction projects. Journal of Computing in Civil Engineering, 31(1), 04016042 .

https://doi.org/10.1061/(ASCE)CP.1943-5487.0000613 